\title{
Adapting life to the reality of diabetes
}

Hossein Namdar Areshtanab, ${ }^{1}$ Hossein Karimi Moonaghi, ${ }^{2}$ Leila Jouybari, ${ }^{3}$ Vahid Zamanzadeh ${ }^{1}$ and Hossein Ebrahimi ${ }^{1}$

${ }^{1}$ Faculty of Nursing and Midwifery, Tabriz University of Medical Sciences, Tabriz, Islamic Republic of Iran (Correspondence to: Hossein Namdar Areshtanab: namdarh@tbzmed.ac.ir). ${ }^{2}$ Faculty of Nursing and Midwifery, Mashhad University of Medical Sciences, Mashhad, Islamic Republic of Iran. ${ }^{3}$ School of Nursing and Midwifery, Golestan University of Medical Sciences, Gorgan, Islamic Republic of Iran.

\begin{abstract}
Background: Diabetes is one of the most challenging and burdensome chronic diseases of the 21st century. Adaptation to disease is a mental, multidimensional, interactive process and is influenced by social and cultural factors. It should be explained in the cultural context of each society with qualitative studies.
\end{abstract}

Aims: In this study, we explored the subjective experiences of adaptation to type 2 diabetes among Iranian patients.

Methods: This was a qualitative study using a grounded theory approach. Purposeful sampling was used initially, followed by theoretical sampling based on derived codes and categories as the sampling method. Twenty patients as main participants and 7 from the healthcare system and family members were selected based on a purposeful and theoretical sampling method. Data were collected through semistructured and deep interviews. Data were analysed using the approach of Strauss and Corbin simultaneous with data collection.

Results: Five categories that emerged from the data included: perceived threat of disease, reality compliance, comprehensive reconstruction, normalization of living with illness, and return to resources. Finally, data analysis on selective coding led to recognition of "endeavour to reconstruction of life" as the core variable. The core variable showed the way participants adapted to diabetes.

Conclusions: This study showed that the process of adaptation to diabetes has a dynamic nature in which participants make major changes in their cognitive, emotional and behavioural structures in order to have a normal life.

Keywords: Diabetes mellitus, psychological adaptation, grounded theory

Citation: Namdar Areshtanab H; Karimi Moonaghi H; Jouybari L; Zamanzadeh V; Ebrahimi H. Adapting life to the reality of diabetes. East Mediterr Health J. 2018;24(8):729-735. https://doi.org/10.26719/2018.24.8.729

Received: 13/10/15; accepted: 12/06/17

Copyright (c) World Health Organization (WHO) 2018. Some rights reserved. This work is available under the CC BY-NC-SA 3.o IGO license (https:// creativecommons.org/licenses/by-nc-sa/3.o/igo).

\section{Introduction}

Diabetes mellitus is one of the most challenging and burdensome chronic diseases of the 21st century (1). It currently affects $\sim 285$ million adults worldwide and this is expected to rise to $>400$ million adults by 2030 (2). Type 2 diabetes mellitus is responsible for $>90 \%$ of all cases of diabetes (3). Most new patients with diabetes are from developing countries and it seems that the Middle East is among the regions that will have the largest increase in prevalence by 2030 . The prevalence of diabetes is $\sim 8.7 \%$ in Iranians (4).

After medical diagnosis of chronic illness (e.g., diabetes), patients are confronted with new situations that challenge their habitual coping strategies and go through a process of psychosocial adaptation (5). Living with diabetes mellitus has been described as a dynamic personal transitional adaptation (6). The experience of living with chronic disease is a continuous, progressive and complex process that can result in adaptation to and management of the disease. Adaptation and management in diabetes are simultaneous and interdependent as the person comes to terms with the illness, gains support from caregivers, creates relationships with others, and learns about the illness and its management (7). Accurate understanding of the adaptation process is necessary in the management of the disease (8). Studies have shown that adaptation to diabetes is a complex interactive, multidimensional and subjective process, and is influenced by different factors and occurs in a social context (9). Available literature is based on studies conducted in western societies that differ in terms of cultural and social backgrounds from Iranian society. Moreover, the studies have shown that sociocultural context could influence the illness and outcome of the process of adaptation to disease $(10,11)$. The aim of this study was to explore adaptation to type 2 diabetes in Iranian patients.

\section{Methods}

\section{Study design and participants}

This was a qualitative study using a grounded theory approach. Grounded theory is especially suitable for analysing social processes, as it rises above merely describing a topic, and instead facilitates a deeper understanding without losing parts and details (12). Following approval (No. 900603) by the Ethics Committee of the Mashhad 
University of Medical Sciences, Islamic Republic of Iran, informed consent was obtained from all participants who met the inclusion criteria. All participants were assured that their personal data would remain confidential. Time and location were chosen by agreement of the participants. Examples of interview questions were as follows: Can you tell me how and when you discovered that you had diabetes? Can you tell me how you live with diabetes? Can you tell me how you feel about your diabetes now?

A purposive sample of 20 patients was recruited. Patients were selected on the basis of the following inclusion criteria: confirmed diagnosis of type 2 diabetes mellitus for $\geq 2$ years; awareness of their diagnosis; cognitive and physical ability to participate; and willingness to participate. Theoretical sampling was used to focus the data collection, enrich the categories that emerged, and guide where to go for the coming data collection. Therefore, there were 3 categories of participants: 20 patients with diabetes, 4 health professionals and 3 spouses.

\section{Data collection}

Data were collected via in-depth, semi structured, faceto-face interviews conducted between September 2013 and August 2014. Seventeen interviews were private and conducted at the participant's discretion with regard to place and time by the Diabetes Association of Iran, Tabriz Branch. Due to the participants' working conditions, 3 of the interviews were undertaken in a private room within Tabriz Faculty of Nursing and Midwifery. Fifteen interviews were conducted in Persian and 5 in Turkish by H.N.A (native language of the authors is Turkish). Each participant was interviewed only once. The analysis was conducted in Persian and, for the purposes of this paper, translated into English. Participants were asked about their experiences of living with and confronting diabetes. The interviews were tape-recorded and transcribed verbatim. The first set of interviews lasted 60-80 minutes and the final series lasted 40-50 minutes (mean time of each interview was 45 minutes). Data collection continued until saturation was achieved; that is, until no new code emerged from the analysis.

Analysis of the interview texts began after the first interview had been conducted and transcribed. Data were analysed as described by Strauss and Corbin (12). At the first level of coding, the transcribed interviews were analysed using line-by-line or segment-by-segment coding guided by questions such as "What is being expressed here?" and "What does it mean?" This initial coding process led to segmentation of the data into codes. These codes were identified and labelled according to their meaning and the actions found in the data. Comparisons of differences and similarities were made continuously, and emerging codes with similar content were grouped together into categories. Categories were labelled in a more abstract way, based on the phenomena they represented and in relation to the meanings and actions found in the data. The first impression during the analysis was that participants had experienced a new sensation that differed from their former experiences of adaptation. During the next step, focused coding was performed and the most meaningful codes were selected. At this point, the core category "endeavour to reconstruction of life" was developed, as well as categories: perceived threat of disease, reality compliance, comprehensive reconstruction, normalization of living with illness, and return to resources for adapting to type 2 diabetes. During the entire analysis, constant comparisons were made between parts of the data and between different categories to capture similarities and differences, as well as relationships among the various categories grounded in the data. Data collection progressed simultaneously with the analysis and coding process. Memos consisted of the researchers' thoughts about the respondents' statements during the interviews, and how the respondents' statements fitted together was also analysed. An initial conceptual model was developed by relating categories to each other and describing processes related to "What's going on?" and "What is it all about?" During the theoretical sampling phase, categories were refined and saturated using additional information acquired by conducting further interviews and by recoding available data. Sample selection was terminated when new data ceased to add anything new to the final model. Twelve interviews were based on a requirement of theoretical sampling.

\section{Results}

Among the participants, 11 (55\%) were male, the average age was 47.8 (12.0) years, and 19 (95\%) were married. Eight (40\%) had a lower educational background (illiterate to diploma), 6 (30\%) had a diploma and $6(30 \%)$ had a higher education background (college graduates). Most women were unemployed while most men were employed and 6 of them were retired. Participants averaged 10.26 (7.07) years living with a diagnosis of diabetes and $10(50 \%)$ participants required daily insulin injection. Ten participants had a weak economic situation. Five categories that emerged from the data included: perceived threat of disease, reality compliance, comprehensive reconstruction, normalization of living with illness, and return to resources (Table 1).

Using a grounded theory approach in the qualitative design of the study led to in-depth understandings of the how and why contextual changes in participant perceptions, activities, interactions and emotional responses over time. All the main categories were related and subordinated to the core category.

Finally, data analysis on selective coding and writing the storyline, making use of diagrams, and reviewing and sorting of memos led to recognition of "endeavour to reconstruction of life" as the core category and the integration of concepts. Endeavour to reconstruction of life appeared frequently in the data during all stages of the process.

The participants experienced symptoms resulting from their diseases. Most participants with exacerbating, continuing symptoms decided to see a doctor (perceived 


\begin{tabular}{|c|c|c|}
\hline Core variable & Main themes & Subthemes \\
\hline \multirow[t]{5}{*}{ Endeavour to reconstruction of life } & Perceived threat of disease & $\begin{array}{l}\text { Confront with new symptoms and signs } \\
\text { Personal processing } \\
\text { Coping with signs and symptoms } \\
\text { Receiving a diagnosis of diabetes }\end{array}$ \\
\hline & Acceptance of reality & $\begin{array}{l}\text { Acceptance of diabetes } \\
\text { Seeking information } \\
\text { Initial imaging of disease } \\
\text { Initial self-management }\end{array}$ \\
\hline & Comprehensive reconstruction & $\begin{array}{l}\text { Self-reconstruction } \\
\text { Reconstruction in the understanding of disease } \\
\text { Life reconstruction } \\
\text { Advanced self-management }\end{array}$ \\
\hline & Normal life with the disease & $\begin{array}{l}\text { Return to activities of daily } \\
\text { living and continuing a healthy lifestyle }\end{array}$ \\
\hline & Return to resources & $\begin{array}{l}\text { Individual resources } \\
\text { Family resources } \\
\text { Social resources }\end{array}$ \\
\hline
\end{tabular}

threat of disease). After receiving a diagnosis, they had varied reactions from denial to acceptance. The participants then began to gain information about diabetes from different sources and processing of the disease in order to manage (acceptance of reality). After years of living with this disease, the participants found that superficial management alone was not enough and comprehensive efforts for effective control of the disease were needed (comprehensive reconstruction). The outcome of comprehensive reconstruction was a normal life with diabetes (normal life with the disease). Factors (such as return to resources category) can affect the process of adjusting to diabetes.

\section{Perceived threat of disease}

We measured the cognitive, emotional and behavioural reactions of participants from experiencing the first warning signs and symptoms to receiving a definitive diagnosis of diabetes. This category included 4 subcategories.

\section{Confront with new symptoms and signs}

This refers to awareness of the abnormal signs and symptoms that were expressed by most of the participants. These symptoms were differentiated by features such as location (depending on the organs involved), frequency and duration of initial symptoms. The most common symptoms were extreme thirst, urinary frequency, visual problems and spontaneous opening of sutured wounds. Women and highly educated participants had greater health awareness and were more prone to health-related activities. However, a few of the participants did not express the warning signs due to a positive history of the illness in their family. A 35-year-old woman remarked: "After the removal of my fallopian tubes, I saw one day that my sutured incision had opened spontaneously while my wound had not recovered."

\section{Personal processing}

Personal processing refers to the participants' interpretation of physical signs and symptoms and their causes. There were 2 kinds: attribution of symptoms to diabetic causes, and attribution of symptoms to nondiabetic causes. Most participants knew the symptoms in association with nondiabetic causes. Misinterpretation of the signs and symptoms can lead to a delay in healthcare-seeking behaviour. However, some participants with a higher education level and a positive family history of diabetes suspected that they had the disease. A 55-year-old man stated: "I was extremely thirsty. I thought I might have a cold."

\section{Coping with signs and symptoms}

Participants engaged in activities to reduce their sign and symptoms. These activities included self-remedy and waiting to change.

"Sometimes, I did not feel good. I had fever and chill. I was eating everything, but again I had shiver. I thought that I had cold, so I took an acetaminophen tablet, and then I expected to feel better." (6o-year-old woman).

"I had a feeling of fatigue and muscle soreness while I hadn't heavy physical work, I told myself wait and see." (45-year-old man)

"My husband had some numbness and weakness in his hands and foot. I told him to saw a doctor. But he ignored and did not go to the doctor." (wife of participant)

\section{Receiving a diagnosis of diabetes}

Exacerbation and persistence of symptoms with disruption of function, and acquisition of information from other sources, resulted in most participants deciding to see a doctor. A 61-year-old man stated: "After some time of suffering from frequent urination and itching, I shared my problem with my wife and she told me that I should see a doctor. I went to see a doctor and after visiting I found out that I suffer from diabetes." 


\section{Acceptance of reality}

We measured cognitive, emotional and behavioural reactions of participants after receiving a diagnosis of diabetes. This category included 4 subcategories.

\section{Acceptance of diabetes}

Most participants reacted to their diagnosis with denial and protest. However, with time, repetition of tests and confirmation of the diagnosis by other doctors, they eventually accepted it.

"After that I became aware of my disease, because of negative history of diabetes in my family, I did not expect to have the disease, I asked why I was infected." (57-year-old man)

"The majority of patients when first time informed of their disease are shocked and cry and think they have no hope for life." (Physician)

\section{Seeking information}

Information seeking can be divided into active and inactive forms. In the active form, those participants who were highly educated searched for information in magazines and online. In the passive form, participants gained information inadvertently.

"After my sutured incisions opened spontaneously, I searched the online and found that one of the causes can be diabetes." (35-year-old woman, high educational level)

"When I turned my car radio on, I realized that they were discussing diets for diabetics." (50-year-old man)

\section{Initial imaging of disease}

After obtaining initial information, most participants gained initial understanding about the causes, course and consequences of the disease. A 51-year-old man commented: "I thought that the disease is short-term and caused by job stress."

\section{Initial self-management}

Most of the participants reported taking the prescribed medication, diet and blood glucose control as the primary management of their illness. A 41-year-old woman remarked:

"After daily insulin injection, I ate my breakfast and working at home. After resting, I walking in the evening."

\section{Comprehensive reconstruction}

Comprehensive reconstruction refers to the participants' reconsideration and reappraisal of themselves, their illness and their life, in order to control diabetes effectively and achieve normalization of life.

\section{Self-reconstruction}

Self-reconstruction included modifying coping styles, identification with successful patients with type 2 diabetes, disclosing your illness to others, and internal locus of control (belief that they can influence diabetes and its outcomes).

"Now, I prepare to participate in scientific studies about diabetes mellitus in order to progress in the treatment of it, while previously I had no such intention." (meaning-based coping; 43-year-old man)
"For 48 years my aunt has had type 2 diabetes mellitus and she lives comfortably with it. I always use her as a model on life with diabetes and I use her guidance in diabetes control." (identification; 61-year-old woman)

"To choose the wrong style of life I blame myself for diabetes now." (internal locus of control; 57-year-old woman)

\section{Reconstruction in the understanding of disease}

Reconstruction in the understanding of disease included finding benefits in the illness and comparison of diabetes mellitus with other diseases.

"I already had a low physical activity level and I ate fatty and fried foods. Now I try to walk every day for at least one half hour and I eat more low-fat and low cholesterol foods such as vegetables and fruits." (50-year-old woman)

\section{Life reconstruction}

Life reconstruction included modifying goals, expectations and balance between work and leisure. A 57-year-old man stated: "Before my illness, I wanted to work after retirement. Now I want to retire earlier so that I may buy a garden where I can plant trees and get relaxation."

\section{Advanced self-management}

Advanced self-management included secondary and preventive management.

"I felt like I was lethargic and I sweat. I noticed that my blood sugar was low and immediately I ate some sugar and after a while I felt that I was fine." (60-year-old woman)

"Now I find that when I go biking or hiking I have a piece of chocolate or fresh fruit in my bag that I use in case of necessity." (60-year-old man)

\section{Normal life with the disease}

Normal life included return to activities of daily living and continuing a healthy lifestyle. A 45-years-old woman stated: "Sometimes I am so immersed in daily life that I forget I have diabetes."

\section{Return to resources}

Return to resources included 3 subcategories: individual, family and social resources. Individual resources included beliefs, personal background, and previous experience. Social resources included family and community.

"Having diabetes means death." (45-year-old woman)

"Following this illness, sexual problems arise; there is no one that can give clear guidance and help you in this regard." (56-year-old man)

"The supportive role of governmental and nongovernmental organizations is important in diabetes control. These organizations can develop training to reduce costs and prevent diabetes". (nurse)

\section{Discussion}

We aimed to understand the process of adaptation to type 2 diabetes. Data analysis showed that participants' perception was an important component in this process. Most participants experienced symptoms including dry mouth, excessive thirst, frequent urination and visual problems resulting from other diseases. The results of 
this study were congruent with other studies (13-15). However, some participants who had previous experience of diabetes in

family members, even without experiencing the warning signs themselves, frequently saw a doctor for a check-up. Prior experience in a family member with diabetes could result in susceptibility to greater consideration of one's own health. If a person perceives himself susceptible to diabetes, they will tend to take preventive action (16). In the present study, most participants attempted to wait and see or resorted to self-remedy to reduce their symptoms, owing to their incorrect interpretations of their signs and symptoms. According to the self-regulatory model, individuals respond to threats with cognitive representation, coping and the appraisal of consequences (17). Most participants with exacerbating, continuing symptoms decided to see a doctor. Our results seemed to be congruent with other studies $(14,18)$.

After receiving a diagnosis, most participants began to deny the reality and protested against it. However, with time, repetition of tests and confirmation of diagnosis by several doctors, the participants accepted their disease (19).

They then began to acquire information about their disease from different sources in order to manage it. Sources of information were physicians, other patients, nurses, the internet, magazines and books, and personal and social factors affected the selection of resources $(20,21)$. Participants then began to shape their beliefs about the causes, course and consequences of their illness. Other studies have shown that they knew diabetes to be a prolonged illness with physical, mental and social complications $(22,23)$. Understanding the nature of the disease affected participants' behaviour (24). Such behaviour is focused on adherence to diet, physical activity, taking prescribed medication, and daily blood sugar control $(25,26)$. After years of living with this disease, patients find that superficial compliance with medication orders, diet and physical activity is not enough and cognitive, emotional and behavioural comprehensive efforts for effective control of the disease and leading a normal life are needed (27). Following the reconstruction of self, their illness and life, participants can continue to play individual, social roles and the disease is not a dominant preoccupation (28-30). Factors such as communication with healthcare providers, and individual, educational and family backgrounds can affect diabetes self-management (31-33).

The obvious contribution of this study was in the generation of the social and psychological process of endeavour to reconstruction of life that accounted for variation in change over time, context and behaviour in adapting to type 2 diabetes in Iranian patients. This was a small study and carried out in the national context of the Islamic Republic of Iran. Thus, caution is needed in generalizing the findings to other countries. Also, the study was performed exclusively in urban areas. We believe that it is necessary to conduct a population-based survey to confirm these findings.

\section{Conclusions}

The purpose of the present study was to explore the subjective experiences of adaptation to diabetes among Iranian patients with type 2 diabetes. We showed that experiencing diabetes is an event that is perceived uniquely by every patient that can significantly affect perception and cause temporary and permanent changes in their lives. Also, the adaptation process consisted of integrated but distinct phases that were nonlinear for each person; however, they were consistent among the participants. Understanding how Iranian people with diabetes become adapted is important to health professionals involved in caring. Health professionals can help patients cope by implementing effective interventions that include reinforcing facilitating factors and modifying hindering factors, giving greater attention to patients' spiritual needs, helping them find meaning in their lives, focusing more attention on family, and considering the context of the patients. The findings could be utilized in education of nursing students and physicians and families of patients with diabetes. They could also be used to design a context-adapted tool adapted to measure adjustment to type 2 diabetes.

\section{Acknowledgements}

This paper is the result of an approved thesis in MUMS (no. 900603), funded by MUMS Vice Presidency for Research Purposes. The authors wish to thank the Vice Chancellor in Research in Mashhad and Tabriz Universities of Medical Sciences who supported this study, as well as all participants and cooperation of Tabriz Branch Diabetes Association for their help in conducting this research.

Funding: None.

Competing interests: None declared. 


\section{Adapter les habitudes de vie à la réalité du diabète \\ Résumé}

Contexte: Le diabète est l'une des maladies chroniques les plus complexes et pesantes du vingt et unième siècle. L'adaptation à la maladie implique un processus mental, multidimensionnel et interactif, qui est influencé par des facteurs sociaux et culturels. Elle doit ainsi être appréhendée par le prisme du contexte culturel de chaque société, à l'aide d'études qualitatives.

Objectif : Dans la présente étude, nous avons analysé les expériences subjectives de l'adaptation au diabète de type 2 parmi des patients iraniens.

Méthodes : Il s'agissait d'une étude qualitative reposant sur la méthodologie de la théorie enracinée. Un échantillonnage ciblé a tout d'abord été utilisé, suivi d'un échantillonnage théorique reposant sur des codes et catégories dérivés. Vingt patients ont été sélectionnés à l'aide des méthodes d'échantillonnage ciblé et théorique. Les données ont été recueillies au moyen d'entretiens semi-structurés et approfondis, et ont été analysées simultanément à l'aide de l'approche de Strauss et Corbin.

Résultats : Les cinq catégories qui se sont dégagées des données recueillies incluaient : la menace perçue de la maladie, le fait de se conformer à la réalité, la reconstruction globale, la normalisation associée au fait de vivre avec la maladie, et le retour aux valeurs de base (individuelles, familiales et sociales). Enfin, l'analyse des données portant sur le codage sélectif a mené à l'identification de «l'effort de reconstruction de sa propre existence » comme variable fondamentale. Cette variable fondamentale a montré la façon dont les participants s'adaptaient au diabète.

Conclusion : La présente étude a révélé que le processus d'adaptation au diabète est de nature dynamique. Les participants modifient en effet considérablement leurs structures cognitives, émotionnelles et comportementales de façon à mener une vie normale.

$$
\text { تحييف الحياة مع حقيقة السكري أريشتانب، حسين موناجي، ليلى جويباري، وحيد زمانز ادة ، حسين إبراهيمي }
$$

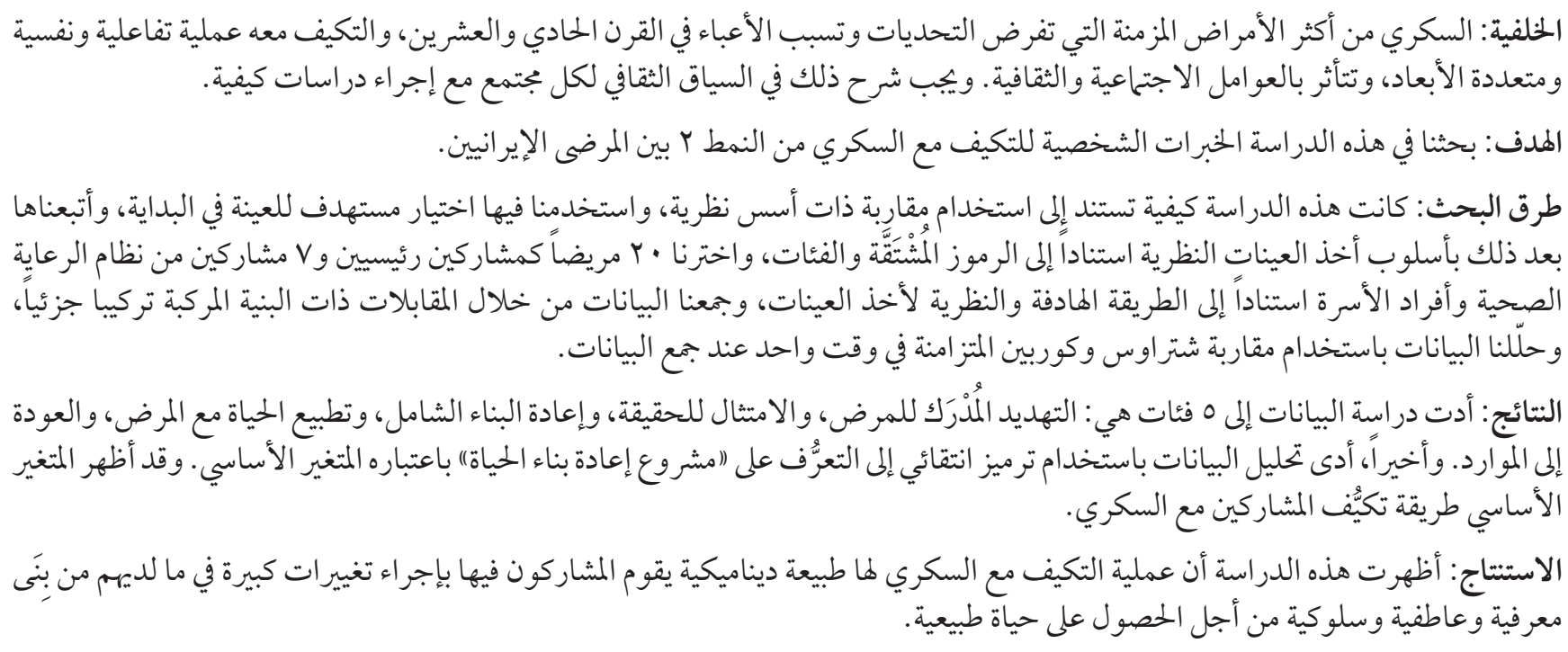

\section{References}

1. Tuncay T, Musabak I, Gok DE, Kutlu M. The relationship between anxiety, coping strategies and characteristics of patients with diabetes. Health Qual Life Outcomes. 2008 10 13;6(1):79. https://doi.org/10.1186/1477-7525-6-79 PMID:18851745

2. Diabetes. Fact sheet. Updated November 2017 (http://www.who.int/mediacentre/factsheets/fs312/en/, accessed 30 January 2018).

3. Olshansky E, Sacco D, Fitzgerald K, Zickmund S, Hess R, Bryce C, et al. Living with diabetes: normalizing the process of managing diabetes. Diabetes Educ. 2008 Nov-Dec;34(6):1004-12. https://doi.org/10.1177/0145721708327304 PMID:19075082

4. Harati H, Hadaegh F, Saadat N, Azizi F. Population-based incidence of type 2 diabetes and its associated risk factors: results from a six-year cohort study in Iran. BMC Public Health. 200906 16;9(1):186. https://doi.org/10.1186/1471-2458-9-186 PMID:19531260

5. Chan FE, Da Silva Cardoso EE, Chronister JA. Understanding psychosocial adjustment to chronic illness and disability: A handbook for evidence-based practitioners in rehabilitation. Springer Publishing; 2009.

6. Gois CJ, Ferro AC, Santos AL, Sousa FP, Ouakinin SR, do Carmo I, et al. Psychological adjustment to diabetes mellitus: highlighting self-integration and self-regulation. Acta Diabetol. 2012 Dec;49(S1) Suppl 1:S33-40. https://doi.org/10.1007/s00592-010-0191-7 


\section{PMID:20473694}

7. Le Mone P, Burke K, Dywer T, Levett-Jones T, Moxham L, Reid-Searl K, et al. Medical-surgical nursing. Critical thinking for person-centred care, 3rd edition. Pearson Australia; 2014.

8. Duangdao KM, Roesch SC. Coping with diabetes in adulthood: a meta-analysis. J Behav Med. 2008 Aug;31(4):291-300. https://doi. org/10.1007/s10865-008-9155-6 PMID:18493847

9. Ambrosio L, Senosiain García JM, Riverol Fernández M, Anaut Bravo S, Díaz De Cerio Ayesa S, Ursúa Sesma ME, et al. Living with chronic illness in adults: a concept analysis. J Clin Nurs. 2015 Sep;24(17-18):2357-67. https://doi.org/10.1111/jocn.12827 PMID:25951949

10. Habib TZ, Rahman S. Psycho-social aspects of AIDS as a chronic illness: social worker role perspective. Antrocom. 2010;6(1):7989 .

11. Gomersall T, Madill A, Summers LKM. A metasynthesis of the self-management of type 2 diabetes. Qual Health Res. 2011 Jun;21(6):853-71. https://doi.org/10.1177/1049732311402096 PMID:21429946

12. Corbin J, Strauss A. Basics of qualitative research: techniques and procedures for developing grounded theory. Sage; 2008

13. Parry O, Peel E, Douglas M, Lawton J. Patients in waiting: a qualitative study of type 2 diabetes patients' perceptions of diagnosis. Fam Pract. 2004 Apr;21(2):131-6. https://doi.org/10.1093/fampra/cmh203 PMID:15020378

14. Obidiya OS, Chima IE, Ekadi TS, Ilodigwe EE. Health seeking behaviour among adult residents of Yenagoa city, Nigeria. Continental J Pharm Sci. 2011;5(2):14.

15. Abdoli S, Ashktorab T, Ahmadi F, Parvizi S, Dunning T. The empowerment process in people with diabetes: an Iranian perspective. Int Nurs Rev. 2008 Dec;55(4):447-53. https://doi.org/10.1111/j.1466-7657.2008.00664.x PMID:19146557

16. Hjelm K, Atwine F, Hjelm K. Health-care seeking behaviour among persons with diabetes in Uganda: an interview study. BMC Int Health Hum Rights. 201109 26;11(1):11. https://doi.org/10.1186/1472-698X-11-11 PMID:21943099

17. Harvey JN, Lawson VL. The importance of health belief models in determining self-care behaviour in diabetes. Diabet Med. 2009 Jan;26(1):5-13. https://doi.org/10.1111/j.1464-5491.2008.02628.x PMID:19125754

18. Longo DR, Schubert SL, Wright BA, LeMaster J, Williams CD, Clore JN. Health information seeking, receipt, and use in diabetes self-management. Ann Fam Med. 2010 Jul-Aug;8(4):334-40. https://doi.org/10.1370/afm.1115 PMID:20644188

19. Corbin JM, Strauss A. Unending work and care: managing chronic illness at home. San Francisco: Jossey-Bass; 1988.

20. Kalantzi S, Kostagiolas P, Kechagias G, Niakas D, Makrilakis K. Information seeking behavior of patients with diabetes mellitus: a cross-sectional study in an outpatient clinic of a university-affiliated hospital in Athens, Greece. BMC Res Notes. 2015 Feb; 20;8:48

21. Cutilli CC. Seeking health information: what sources do your patients use? Orthop Nurs. 2010 May-Jun;29(3):214-9. PMID:20505493

22. Fukunaga LL, Uehara DL, Tom T. Perceptions of diabetes, barriers to disease management, and service needs: a focus group study of working adults with diabetes in Hawaii. Prev Chronic Dis. 2011 Mar;8(2):A32. PMID:21324246

23. Yilmaz-Aslan Y, Brzoska P, Bluhm M, Aslan A, Razum O. Illness perceptions in Turkish migrants with diabetes: a qualitative study. Chronic Illn. 2014 Jun;10(2):107-21. https://doi.org/10.1177/1742395313501207 PMID:23986085

24. Hale ED, Treharne GJ, Kitas GD. The common-sense model of self-regulation of health and illness: how can we use it to understand and respond to our patients' needs? Rheumatology (Oxford). 2007 Jun;46(6):904-6. https://doi.org/10.1093/rheumatology/ kemo6o PMID:17449488

25. Thorne S, Paterson B, Russell C. The structure of everyday self-care decision making in chronic illness. Qual Health Res. 2003 Dec;13(10):1337-52. https://doi.org/10.1177/1049732303258039 PMID:14658350

26. Ellison GC, Rayman KM. Exemplars' experience of self-managing type 2 diabetes. Diabetes Educ. 1998 May-Jun;24(3):325-30. https://doi.org/10.1177/014572179802400307 PMID:9677950

27. Paterson B, Thorne S, Crawford J, Tarko M. Living with diabetes as a transformational experience. Qual Health Res. 1999 Nov;9(6):786-802. https://doi.org/10.1177/104973299129122289 PMID:10662259

28. Choi HJ, Hong YS. Transformational experience of a student nurse with diabetes: a case study. Taehan Kanho Hakhoe Chi. 2007 Mar;37(2):192-200. https://doi.org/10.4040/jkan.2007.37.2.192 PMID:17435403

29. Lin CC, Anderson RM, Hagerty BM, Lee BO. Diabetes self-management experience: a focus group study of Taiwanese patients with type 2 diabetes. J Clin Nurs. 2008 Mar;17(5a) 5a:34-42. https://doi.org/10.1111/j.1365-2702.2007.01962.x PMID:18093120

30. Mendenhall E, McMurry HS, Shivashankar R, Narayan KM, Tandon N, Prabhakaran D. Normalizing diabetes in Delhi: a qualitative study of health and health care. Anthropol Med. 2016 Dec;23(3):295-310. https://doi.org/10.1080/13648470.2016.1184010 PMID:27328175

31. Wilkinson A, Whitehead L, Ritchie L. Factors influencing the ability to self-manage diabetes for adults living with type 1 or 2 diabetes. Int J Nurs Stud. 2014 Jan;51(1):111-22. https://doi.org/10.1016/j.ijnurstu.2013.01.006 PMID:23473390

32. Lundberg PC, Thrakul S. Type 2 diabetes: how do Thai Buddhist people with diabetes practise self-management? J Adv Nurs. 2012 Mar;68(3):550-8. https://doi.org/10.1111/j.1365-2648.2011.05756.x PMID:21711465

33. Cotugno JD, Ferguson M, Harden H, Colquist S, Stack AA, Zimmerman JI, et al. "I wish they could be in my shoes": patients' insights into tertiary health care for type 2 diabetes mellitus. Patient Prefer Adherence. 2015 Nov 17;9(9):1647-55. PMID:26604714 